\title{
Tuning of ionic mobility to improve the resistive switching behavior of $\mathrm{Zn}$-doped $\mathrm{CeO}_{2}$
}

Shania Rehman ${ }^{1}$, Honggyun Kim ${ }^{1}$, Muhammad Farooq Khan ${ }^{1}$, Ji-Hyun Hur ${ }^{1}$, Anthony D. Lee $\mathbb{D}^{2}$ \& Deok-kee Kim ${ }^{1 *}$

Correlation between the resistive switching characteristics of $\mathrm{Au} / \mathrm{Zn}$-doped $\mathrm{CeO}_{2} / \mathrm{Au}$ devices and ionic mobility of $\mathrm{CeO}_{2}$ altered by the dopant concentration were explored. It was found that the ionic mobility of $\mathrm{CeO}_{2}$ has a profound effect on the operating voltages of the devices. The magnitude of operating voltage was observed to decrease when the doping concentration of $\mathrm{Zn}$ was increased up to $14 \%$. After further increasing the doping level to $24 \%$, the device hardly exhibits any resistive switching. At a low doping concentration, only isolated $\mathrm{V}_{\mathrm{o}}$ existed in the $\mathrm{CeO}_{2}$ lattice. At an intermediate doping concentration, the association between dopant and $V_{0}$ formed $\left(Z n, V_{o}\right)^{\times}$defect clusters. Low number density of these defect clusters initially favored the formation of $\mathrm{V}_{\mathrm{o}}$ filament and led to a reduction in operating voltage. As the size and number density of $\left(Z n, V_{0}\right)^{\times}$defect clusters increased at a higher doping concentration, the ionic conductivity was limited with the trapping of isolated $V_{0}$ by these defect clusters, which resulted in the diminishing of resistive switching. This research work provides a strategy for tuning the mobility of $\mathrm{V}_{\mathrm{o}}$ to modulate resistive switching characteristics for non-volatile memory applications.

As existing semiconductor technologies are approaching their physical scaling limits, a new memristive device concept ${ }^{1,2}$ has gained great attention for its use in future highly scalable nonvolatile memories. The switching mechanism in resistive random-access memory (RRAM) is governed by the oxide ion migration and the formation of oxygen vacancy $\left(\mathrm{V}_{\mathrm{o}}\right)$ filament within the metal oxide thin films. The ionic migration is driven by the electric field induced drift motion and concentration gradient dependent diffusion ${ }^{3}$. This drift/diffusion of $V_{o}$ is supposed to play a key role in determining the ultimate resistive switching behavior of the devices. The ionic diffusion coefficient is expressed as $D=\left[V_{o}^{\cdot}\right] \gamma a^{2} \theta e^{\left(-E_{m} / k_{B} T\right)_{4}}$, where $\left[V_{o}^{*}\right]$ is the concentration of oxygen vacancies, $\gamma$ is a constant, $\mathrm{a}$ is the jump distance, $\theta$ is the attempt to escape frequency, $\mathrm{E}_{\mathrm{m}}$ is the oxide ion migration energy barrier, $\mathrm{k}_{\mathrm{B}}$ is the Boltzmann constant, and $\mathrm{T}$ is the temperature. The above expression makes it clear that the diffusion coefficient depends on $\left[V_{o}^{\cdot}\right]$ the mobility of oxygen ion via $e^{\left(-E_{m} / k_{B} T\right)}$. The mobility of the oxygen ions is directly proportional to the ionic conductivity of the oxygen ions. Hence, it can be assumed that the mobility or ionic conductivity of oxygen ions and the concentration of oxygen vacancies are the key parameters to control the resistive switching behavior in RRAM.

The ionic conductivity of pure $\mathrm{CeO}_{2}$ used in this study is not very high because of the low concentration of oxygen vacancies ${ }^{5}$. However, the exceptional sensitivity of ionic conductivity of doped $\mathrm{CeO}_{2}$ associated with doping level have been demonstrated ${ }^{6,7}$. The ionic conductivity of $\mathrm{CeO}_{2}$ can be modulated by doping it with lower valency (bivalent or trivalent) cations. Theoretical studies indicate that $\mathrm{Ce}^{4+} / \mathrm{Ce}^{3+}$ reduction is greatly enhanced when the $\mathrm{CeO}_{2}$ is doped with bivalent or trivalent oxides ${ }^{6}$. When $\mathrm{CeO}_{2}$ is doped with bivalent oxide, $\mathrm{Ce}(\mathrm{IV})$ atoms of host lattice are replaced with bivalent cations, and an $\mathrm{O}$ vacancy is formed in order to compensate the created charge. These created vacancies make the diffusion of $\mathrm{O}$ ions easier, and increase ionic conductivity. The formation of the oxygen vacancy results in the reduction of two neighboring $\mathrm{Ce}$ ions from $\mathrm{Ce}^{4+}$ to $\mathrm{Ce}^{3+7,8}$. This increase in concentration of oxygen vacancies and their mobility on doping with bivalent dopant may control the characteristics of memory devices such as switching speed, operating voltage, and the $\mathrm{R}_{\text {on }} / \mathrm{R}_{\text {off }}$ ratio. Although the resistive switching behavior of $\mathrm{CeO}_{2}$ films has already been investigated ${ }^{9-11}$, the previous studies on the resistive switching characteristics of $\mathrm{CeO}_{2}$ has encountered the demerits of high operating voltage ${ }^{12}$ and a low memory window ${ }^{13}$.

${ }^{1}$ Department of Electrical Engineering, Sejong University, Seoul, 05006, Republic of Korea. ${ }^{2}$ Department of Mechanical Engineering Technology, Farmingdale State College, Farmingdale, New York, 11735, USA. *email: deokkeekim@sejong.ac.kr 
Different strategies such as doping ${ }^{14}$ or interface engineering which includes the introduction of $\mathrm{CeO}_{\mathrm{x}} /$ silicon $(\mathrm{Si})$ interface ${ }^{15}, \mathrm{ZrO}_{\mathrm{y}}$ interfacial layer ${ }^{10}$ or the use of reactive metal electrodes ${ }^{16}$ was adopted for the creation of oxygen vacancies in $\mathrm{CeO}_{2}$ films to reduce the operating voltages and improve endurance. In this study, we have utilized a different approach to modulate the level of oxygen stoichiometry and defects in the $\mathrm{CeO}_{2}$. It is known that bivalent dopants are more efficient for obtaining the lower reduction energy because the bivalent dopant may introduce twice the number of oxygen vacancies in host $\mathrm{CeO}_{2}$ lattice as compared to trivalent dopants at the same doping level ${ }^{6}$ (Supporting information S1). We chose $\mathrm{Zn}^{2+}(0.091 \mathrm{~nm}$ ) as a bivalent dopant having comparable ionic radii with $\mathrm{Ce}^{4+}(0.097 \mathrm{~nm})$, because it not only increases the reducibility of $\mathrm{CeO}_{2}{ }^{17,18}$, but also is economic and easily available compared to high ionic rare earth metal dopants such as $\mathrm{Sm}^{3+}$ and $\mathrm{Ga}^{3+}$. The $\mathrm{Zn}$ doping level in this study was much higher as compared to previous studies, where doping was initiated by using an electric field stimulated diffusion of metal ions from an inserted metal layer ${ }^{10,19,20}$. However, the doping level was kept below the solubility limit ${ }^{21}(20-30 \%)$ to avoid the complexity of the secondary phase evolution of $\mathrm{ZnO}$ in $\mathrm{CeO}_{2}$. Based on previous studies ${ }^{6,22,23}$, it is clear that the dopant incorporation in the $\mathrm{CeO}_{2}$ lattice has a significant influence on the transport properties of $\mathrm{O}$ ions. The interactions between dopants and oxygen vacancies at higher doping levels play an important role in determining the mobility of oxygen ions. The effect of the defect interaction with oxygen vacancies on the resistive switching mechanism has rarely been reported before. At low doping levels, isolated $\mathrm{V}_{\mathrm{o}}$ are created, which results in an increase of mobility of the oxygen ion. At medium doping levels, defect associates or clusters are formed with certain binding or association energy because of interactions between dopants and oxygen vacancies, but the number density of these defect is very low at medium doping levels to affect the mobility of oxygen ions. At higher doping concentrations, the number density of these defect associates increases and prevent oxygen vacancy from being mobile, and they consequently affect the ionic conductivity ${ }^{24-26}$. There are two major factors that determine the association energy of a dopant-oxygen vacancy cluster. The first factor is the Coulombic interaction that corresponds to the electrostatic attraction among the dopant ions and oxygen vacancies, and the second is the elastic interactions that refers to the size mismatch of dopants as compared to the host lattice ${ }^{27-29}$. Hence, the valence and ionic radius of the dopant cations play a key role in modulating the electrical conductivity of doped $\mathrm{CeO}_{2}$. The defect chemistry of $\mathrm{Zn}$-doped $\mathrm{CeO}_{2}$ is given in the Supplementary information S2.

\section{Experimental Details}

Au was deposited as the bottom electrode by an e-beam evaporator with a thickness of $70 \mathrm{~nm}$. $\mathrm{CeO}_{2}$ and $\mathrm{ZnO}$ targets (Superconductor Materials (SCM), USA) were used for the deposition of the active layer in the RF sputtering unit. Prior to the deposition of $\mathrm{CeO}_{2}$, the sputtering chamber was evacuated down to a pressure level of $2 \times 10^{-6}$ Torr. During the deposition, working pressure inside the chamber was 22 mTorr. $\mathrm{Ar}$ and $\mathrm{O}_{2}$ gases with the flow rates of $14 \mathrm{sccm}$ and $2 \mathrm{sccm}$ were introduced into the chamber. The RF-power of the $\mathrm{CeO}_{2}$ target was kept at $150 \mathrm{~W}$. The RF power of the $\mathrm{ZnO}$ target was varied from $35 \mathrm{~W}$ and $45 \mathrm{~W}$ to $55 \mathrm{~W}$ to modulate the doping level in different $\mathrm{Zn}$-doped $\mathrm{CeO}_{2}$ samples. According to the doping levels determined by XPS, the samples are labelled as $6 \mathrm{ZnCeO}_{2}, 14 \mathrm{ZnCeO}$ and $24 \mathrm{ZnCeO}$ for $\mathrm{Zn}$-doped $\mathrm{CeO}_{2}$ samples deposited by the $\mathrm{ZnO}$ sputtering target with RF power of $35 \mathrm{~W}, 45 \mathrm{~W}$, and $55 \mathrm{~W}$, respectively. After deposition, samples were annealed at $500^{\circ} \mathrm{C}$ for 20 minutes in an Ar environment to allow uniform doping. Finally, the top electrode of Au was deposited by an e-beam evaporator with a thickness of $70 \mathrm{~nm}$ and an area of $75 \times 75 \mu \mathrm{m}^{2}$ using a shadow mask. The surface composition and chemical properties were analyzed by a Thermo Fisher Scientific (with K-alpha X-ray source) X-ray photoelectron Spectroscopy (XPS). The Raman spectra were obtained using a Renishaw micro-spectrometer with a laser wavelength of $514 \mathrm{~nm}$ at room temperature. The spot size was $\sim 1 \mu \mathrm{m}$ and the power was maintained at $\sim 1.0 \mathrm{~mW}$ to reduce the heating effects. The electrochemical impedance spectroscopy was performed using a ZIVE SP2 electrochemical workstation (WonATech Co., Ltd, Republic of Korea). The measured frequency ranged from $0.1 \mathrm{~Hz}$ to $1 \mathrm{MHz}$ under a bias voltage of $10 \mathrm{mV}$. The electrical characteristics were measured using an Agilent B1500 semiconductor characterization system at room temperature.

\section{Results and Discussion}

XPS is utilized to determine the elemental composition and valence states of the $\mathrm{Zn}$-doped $\mathrm{CeO}_{2}$ samples. The detailed survey XPS spectra of un-doped $\mathrm{CeO}_{2}$ and $\mathrm{Zn}$-doped $\mathrm{CeO}_{2}$ are shown in Figure S3(a). The spectra revealed the existence of characteristic peaks of $\mathrm{Ce}, \mathrm{Zn}$, and $\mathrm{O}$. In order to calculate the elemental composition and identification of chemical states, the high-resolution $\mathrm{O} 1 \mathrm{~s}, \mathrm{Zn} 2 \mathrm{~d}$, and Ce $3 \mathrm{~d}$ core level spectra are discussed in more detail below. Figure $1(\mathrm{a}, \mathrm{b})$ display the $\mathrm{Zn} 3 \mathrm{~d}$ XPS spectra for un-doped and $\mathrm{Zn}$-doped $\mathrm{CeO}_{2}$ in the binding energy range from $80 \mathrm{eV}$ to $98 \mathrm{eV}$ and from $1015 \mathrm{eV}$ to $1028 \mathrm{eV}$ with different concentrations of $\mathrm{Zn}$ controlled by changing the RF power of the $\mathrm{ZnO}$ target from $35 \mathrm{~W}$ to $55 \mathrm{~W}$ with an increment of $10 \mathrm{~W}$. The spectra in Fig. 1(a) is de-convoluted into two peaks. On the other hand, the spectra in Fig. 1(b) is fitted with one peak. The characteristic peaks of $\mathrm{Zn}$ are observed at $89 \mathrm{eV}$ in Fig. 1(a), and $1022 \mathrm{eV}$ in Fig. 1(b), respectively. This spectrum confirmed the $\mathrm{Zn}$ doping in $\mathrm{CeO}_{2}$. The $\mathrm{Zn}^{2+}$ concentration in each sample was estimated by adding the areas under the curves of the $89 \mathrm{eV}$ and $1022 \mathrm{eV}$ peaks, and dividing by the sum of the areas of all characteristic peaks multiplied by their cross-section of $\mathrm{Ce}^{3+}, \mathrm{Ce}^{4+}, \mathrm{Zn}^{2+}$ and $\mathrm{O}^{2+}$ in the spectra.

In order to analyze the effect of dopant on the surface chemistry and estimate the relative fraction of $\mathrm{Ce}^{4+}$ and $\mathrm{Ce}^{3+}$ oxidation states in the $\mathrm{Zn}$-doped $\mathrm{CeO}_{2}$ samples, the Ce $3 \mathrm{~d}$ spectra was de-convoluted into eight peaks as shown in Fig. 2. The peaks at $885 \mathrm{eV}$ and $903.5 \mathrm{eV}$ are assigned to $\mathrm{Ce}^{3+}$, while $882 \mathrm{eV}, 898 \mathrm{eV}$, and $916.35 \mathrm{eV}$ are attributed to the $\mathrm{Ce}^{4+}$ state ${ }^{30}$. The coexistence of $\mathrm{Ce}^{4+}$ and $\mathrm{Ce}^{3+}$ ions can be seen in each sample. The relative concentration of the $\mathrm{Ce}^{3+}$ species in each sample is calculated by dividing the sum of the integrated areas of the $\mathrm{Ce}^{3+}$ peaks to the total area of all the peaks $\left(\mathrm{Ce}^{3+}\right.$ and $\mathrm{Ce}^{4+}$ species) in the spectrum. The calculated concentration of the $\mathrm{Ce}^{3+}$ ions was $14 \%, 21 \%, 26 \%$, and $22 \%$ in un-doped $\mathrm{CeO}_{2}, 6 \mathrm{ZnCeO}_{2}, 14 \mathrm{ZnCeO}_{2}$ and $24 \mathrm{ZnCeO}_{2}$, respectively. The analysis showed that the $\mathrm{Ce}^{3+}$ concentration was increasing in the samples with the increase in the 


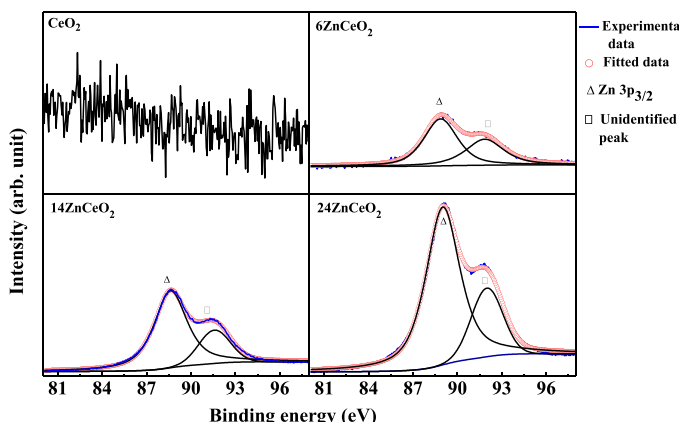

(a)

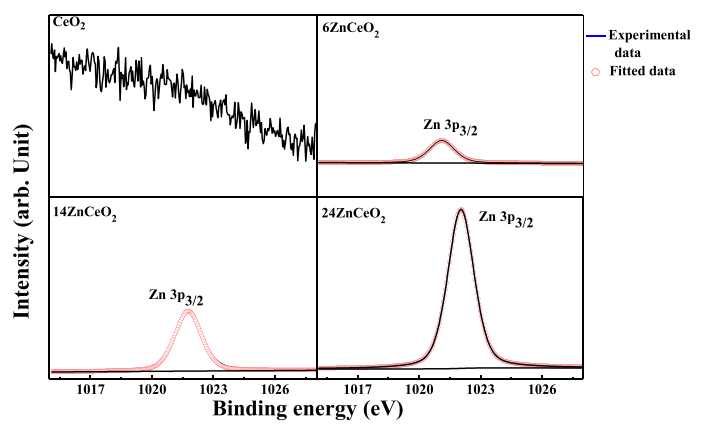

(b)

Figure 1. (a) High resolution XPS spectra of $\mathrm{Zn} 3 \mathrm{p}_{3 / 2}$ in un-doped and $\mathrm{Zn}$-doped $\mathrm{CeO}_{2}$ samples. (b) High resolution XPS spectra of $\mathrm{Zn} 3 \mathrm{p}_{3 / 2}$ in un-doped and $\mathrm{Zn}$-doped $\mathrm{CeO}_{2}$ samples.

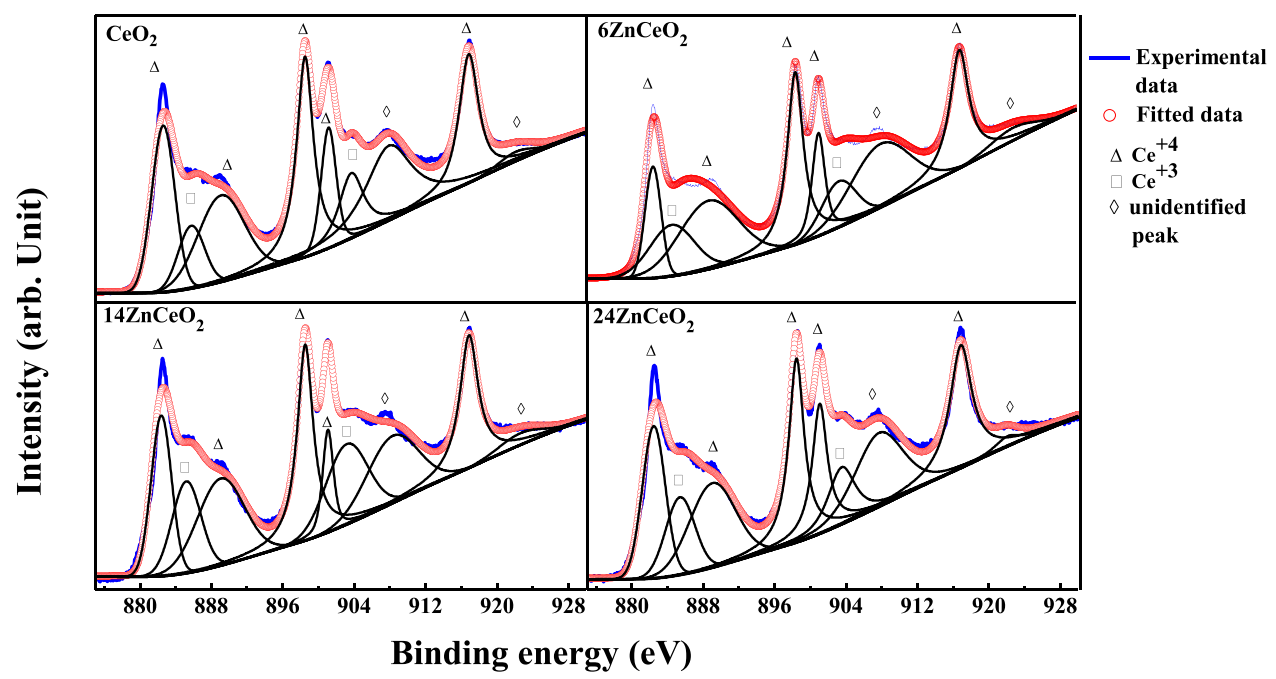

Figure 2. (a) High resolution XPS spectra of $\mathrm{Ce} 3 \mathrm{~d}$ in un-doped and $\mathrm{Zn}$-doped $\mathrm{CeO}_{2}$ samples.

doping concentration. It has been reported that the presence of $\mathrm{Ce}^{3+}$ ions in the $\mathrm{CeO}_{2}$ is linked with the formation of oxygen vacancies ${ }^{8}$. It is described in the previous section that when the $\mathrm{CeO}_{2}$ is doped with bivalent ions, the $\mathrm{Ce}^{4+} / \mathrm{Ce}^{3+}$ reduction is greatly enhanced. When the $\mathrm{Zn}$ dopant substitute was $\mathrm{Ce}^{4+}$, an $\mathrm{O}$ vacancy formed inside the $\mathrm{CeO}_{2}$ lattice. The formation of the oxygen vacancy resulted in the reduction of two neighboring Ce ions from $\mathrm{Ce}^{4+}$ to $\mathrm{Ce}^{3+}$. Thus, the systematic increase in $\mathrm{Ce}^{3+}$ content in the $6 \mathrm{ZnCeO}_{2}$ and $14 \mathrm{ZnCeO}_{2}$ was an indication of more oxygen vacancies on increasing the doping concentration. However, the decrease in $\mathrm{Ce}^{3+}$ content was observed in the $24 \mathrm{ZnCeO}_{2}$ sample on increasing the dopant concentration. The slightly decreased $\mathrm{Ce}^{3+}$ concentration in $24 \mathrm{ZnCeO}_{2}$, which is unlike other doping concentrations indicated that there was a saturation of isolated oxygen vacancies at this point. At low doping concentrations, association between $\mathrm{Ce}^{4+}$ and $\mathrm{V}_{\mathrm{o}}$ was strong, which resulted in the enhancement of $\mathrm{Ce}^{3+}$. As the doping level increased, the association between dopant and $\mathrm{V}_{\mathrm{o}}$ became stronger, which resulted in the formation of $\left(Z n, V_{o}\right)^{\times}$defect clusters, and the preferred substitutional position of dopant was in the defect cluster $\left(Z n, V_{o}\right)^{\times}$. This resulted in a decrease in the reduction process of $\mathrm{Ce}^{4+}$ to $\mathrm{Ce}^{3+}$ by an interaction with nearby $\mathrm{V}_{\mathrm{o}}{ }^{26}$.

The high-resolution O 1s core-level spectra is shown in Figure S3(b) which is de-convoluted into two peaks for further analysis. The peaks in the range of 531.0-532.6 eV can be attributed to the surface oxygen species adsorbed on the oxygen vacancies (i.e., $\mathrm{O}^{-}, \mathrm{OH}^{-}$). However, the binding energy at $529.4 \mathrm{eV}$ was assigned to lattice oxygen $^{31}$. The spectrum was composed of lattice oxygen and chemisorbed oxygen species. For analysis, we only considered the contribution of the peak associated with lattice oxygen. As it can be seen in Figure S3(b), the intensity of the peak is reduced on increasing the doping concentration. As previously discussed, increasing the doping concentration creates more oxygen vacancies. This decrease in the intensity of the peak is associated with the formation of more oxygen vacancies on increasing the doping concentration.

A Raman spectroscopy was employed to study the relative change in vibrational modes and lattice structural characteristics of $\mathrm{CeO}_{2}$ as a function of $\mathrm{Zn}$ doping. Raman spectroscopy is an efficient technique to study symmetry breaking and defect associates in doped $\mathrm{CeO}_{2}^{32}$. This technique is very useful to detect the changes in the bonding atmosphere, because it allows a thorough analysis of the $\mathrm{Ce}-\mathrm{O}$ bonds ${ }^{32,33}$. The excitation laser of wavelength $514 \mathrm{~nm}$ can provide information about bulk of $\mathrm{Zn}$-doped $\mathrm{CeO}_{2}{ }^{22}$. Figure 3 displays the Raman spectrum of $\mathrm{Zn}$-doped $\mathrm{CeO}_{2}$ thin films measured in the range of $400 \mathrm{~cm}^{-1}$ to $700 \mathrm{~cm}^{-1}$. The main Raman-active mode $\left(\mathrm{F}_{2 \mathrm{~g}}\right)$ 


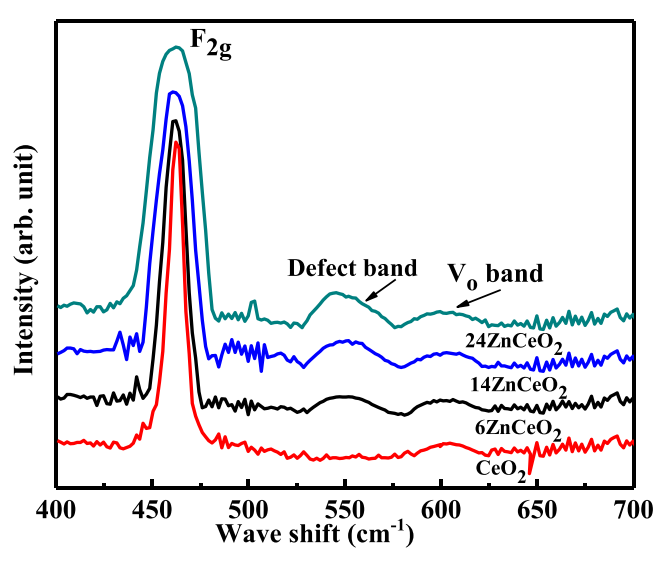

(a)

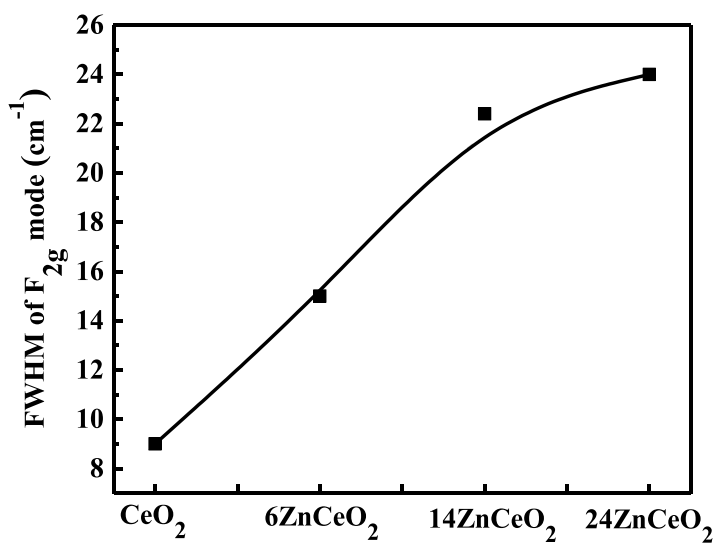

(b)

Figure 3. (a) Raman spectra of un-doped and $\mathrm{Zn}$-doped $\mathrm{CeO}_{2}$ samples. (b) Plot of variation of FWHM of $\mathrm{F}_{2 \mathrm{~g}}$ mode in undoped and $\mathrm{Zn}$ doped $\mathrm{CeO}_{2}$ samples.

in a fluorite-type $\mathrm{CeO}_{2}$ due to $\mathrm{Ce}-\mathrm{O}$ stretching vibration, is located around $462 \mathrm{~cm}^{-134}$. It is considered that the $\mathrm{F}_{2 \mathrm{~g}}$ mode is assigned to the symmetric breathing mode of oxygen ions around the Ce cation, and its position is strongly dependent on the Ce (cation)-O (anion) bond strength ${ }^{35}$. As can be seen in the Raman spectrum of the $\mathrm{Zn}$-doped $\mathrm{CeO}_{2}$, increasing the doping concentration results in an increase in FWHM and a frequency shift of the $\mathrm{F}_{2 \mathrm{~g}}$ peak. This increase in FWHM and a frequency shift are associated with structural disorder induced by the dopant by increasing the dopant concentration ${ }^{36}$.

Additional modes at $555 \mathrm{~cm}^{-1}$ and $610 \mathrm{~cm}^{-1}$ were also observed in the Raman spectra. A Peak at $590 \mathrm{~cm}^{-1}$ originated due to oxygen vacancies and disturbed local symmetry induced by the different sizes of the dopants and a peak at $610 \mathrm{~cm}^{-1}$ in $\mathrm{CeO}_{2}$ is associated with intrinsic oxygen vacancies ${ }^{37,38}$. In this case, different sizes of $\mathrm{Zn}^{2+}$ versus $\mathrm{Ce}^{4+}$ cations were responsible to activate the $555 \mathrm{~cm}^{-1}$ mode in the doped $\mathrm{CeO}_{2}$ samples. The presence of these modes can be associated with the homogeneous incorporation of $\mathrm{Zn}$ within the $\mathrm{CeO}_{2}$ crystal structure and the formation of oxygen vacancies associated with this phenomenon. The oxygen vacancy peak found in the un-doped $\mathrm{CeO}_{2}$, can be associated with the presence of some intrinsic vacancy. As the deposition was performed in a very low $\mathrm{O}_{2}$ atmosphere, it may also have contributed to the formation of oxygen vacancies. The enhancement of the $555 \mathrm{~cm}^{-1}$ mode with the increase in doping concentration was associated with the increase in oxygen vacancies and associated structural disorder on increasing doping concentration.

Electrochemical impedance spectroscopy (EIS) is employed to study the influence of doping on the ionic conductivities of the as-synthesized un-doped and $\mathrm{Zn}$-doped $\mathrm{CeO}_{2}$ samples. Generally, for the case of ionic conductivity materials, the EIS mainly consists of three arcs: the high frequency arc, the middle-frequency arc, and the low frequency tail. The high frequency arc, the middle frequency arc, and the low frequency tail correspond to the grain interior, grain boundaries, and electrode contribution to the overall conductivity of the sample ${ }^{22}$. Figure 4(a) shows the typical Nyquist plots for the $\mathrm{CeO}_{2}, 6 \mathrm{ZnCeO}_{2}, 14 \mathrm{ZnCeO}_{2}$, and $24 \mathrm{ZnCeO}$ samples obtained in air. These plots, which comprised of one semicircle, were different from the typical Nyquist plots of un-doped and $\mathrm{Zn}$-doped $\mathrm{CeO}_{2}$ that consist of two separate semicircles ${ }^{39}$. This difference was assigned to the existence of experimental stray capacitance, which was several orders of magnitude higher than the capacitance of the bulk and grain boundaries of the film ${ }^{40,41}$. Since the existence of stray capacitance makes it difficult to distinguish between the contribution of grain interior and grain boundary, only the additive effect of both resistances can be measured. The equivalent circuit shown in Fig. 4(b) consists of the resistance R and a constant phase element (CPE) in parallel was used for the fitting of Nyquist plot. The CPE is the replacement of ideal capacitor. Mathematically, impedance of the CPE is defined $\mathrm{as}^{42}$

$$
Z=\frac{1}{i w^{\alpha} C_{\alpha}}
$$

where $i, w$, and $\alpha$ are $\sqrt{-1}$, angular frequency and a factor associated with the deviation from ideal resistor, capacitance, and inductor. It corresponds to a resistor, a capacitor and an inductor when $\alpha=0, \alpha=1$ and $\alpha=-1$, respectively. In the actual application of this element, $\alpha$ is defined between 0 and 1 , and this element can be assumed a generalization of a conventional capacitor. $C_{\alpha}$ is the constant phase element. The equivalent circuit shown in Fig. 4(b) and corresponding parameters (R and CPE) were obtained by fitting of the experimental data using ZMAN software. According to the fitted results, the values of $\mathrm{R}$ and CPE are listed in Table 1 and plotted in Figure S4. As is shown in Table 1 and Figure S4, the resistance of $\mathrm{CeO}_{2}$ decreases with the increase in doping concentration up to $14 \%$. With further increase of the doping concentration, a slight increase in the resistance of $24 \mathrm{ZnCeO}_{2}$ was observed. At low doping concentrations, dopant cations substitute the $\mathrm{Ce}^{4+}$ in the lattice structure, form a solid solution and, increases the concentration of isolated oxygen vacancies. This leads to an increase in the ionic conductivity. At intermediate doping concentrations, association between the dopant and $V_{o}$ forms clusters. Both the size and number density of these clusters increases with the doping concentration. For high 

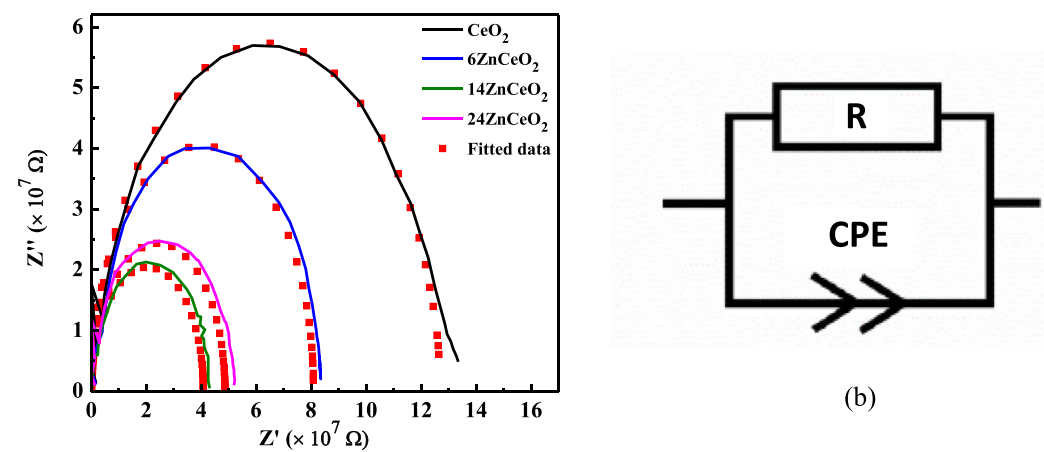

(b)

(a)

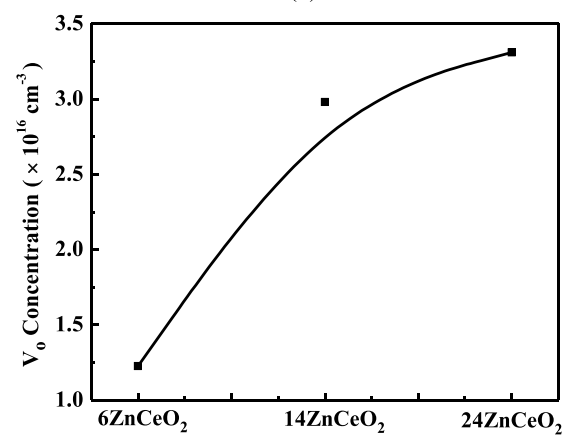

(c)

Figure 4. (a) Electrochemical impedance spectra of un-doped and $\mathrm{Zn}$-doped $\mathrm{CeO}_{2}$ measured in atmosphere at $250^{\circ} \mathrm{C}$. (b) Equivalent circuit to analyze the resistance ' $R$ ' and constant phase element 'CPE'. (c) Variation in concentration of $\mathrm{V}_{\mathrm{o}}$ at different doping levels.

\begin{tabular}{|l|l|l|l|}
\hline Composition & $\mathbf{R}(\Omega)$ & $\mathbf{C P E}\left(\mathbf{F} . S^{(\alpha-1)}\right)$ & $\alpha$ \\
\hline $\mathrm{CeO}_{2}$ & $1.27 \times 10^{7}$ & $5.48 \times 10^{-10}$ & 0.964 \\
\hline $6 \mathrm{ZnCeO}_{2}$ & $8.03 \times 10^{7}$ & $4.44 \times 10^{-10}$ & 0.934 \\
\hline $14 \mathrm{ZnCeO}_{2}$ & $4.08 \times 10^{7}$ & $2.63 \times 10^{-10}$ & 0.927 \\
\hline $24 \mathrm{ZnCeO}_{2}$ & $4.81 \times 10^{7}$ & $3.33 \times 10^{-10}$ & 0.932 \\
\hline
\end{tabular}

Table 1. Parameters extracted from the fitted data using experimentally obtained EIS spectra with equivalent circuit, for undoped and doped $\mathrm{CeO}_{2}$ with different doping levels.

doping concentrations, conductivity is reduced due to decreasing mobility of isolated $\mathrm{V}_{\mathrm{o}}$ by the increased number density of the clusters. The isolated $\mathrm{V}_{\mathrm{o}}$ gets trapped in these $\left(\mathrm{Zn}, \mathrm{V}_{\mathrm{o}}\right)^{\times}$defect clusters and affects the conductivity of the heavily doped sample $e^{8,43,44}$.

The performance of memory devices is associated with the movement of oxygen ions through $\mathrm{V}_{\mathrm{o}}$, under the influence of external electric field. The resistive switching characteristics of these devices are strongly affected by the concentration of the isolated oxygen vacancies or clustered oxygen vacancies. The concentration of isolated $\mathrm{V}_{\mathrm{o}}$ can be obtained by utilizing the chemical capacitance $\mathrm{C}_{\text {chem }}$ extracted by the impedance spectroscopy ${ }^{42}$. The relationship between the concentration of $\mathrm{V}_{\mathrm{o}}$ in the doped $\mathrm{CeO}_{2}$ film and the $\mathrm{C}_{\text {chem }}$ extracted by the impedance spectroscopy is explored by D. Chen et al. ${ }^{42}$. The chemical capacitance is defined as a measure of material's chemical storage ability under the influence of applied potential as follows:

$$
\mathrm{C}_{\mathrm{chem}}=-\frac{8 \mathrm{q}^{2} \mathrm{~V}_{\mathrm{film}}}{\mathrm{kT}}\left(\mathrm{pO}_{2} \frac{\partial\left[\mathrm{V}_{\mathrm{O}}\right]}{\partial \mathrm{pO}_{2}}\right),
$$

where $\mathrm{q}, \mathrm{V}_{\text {film }}$, and $\mathrm{pO}_{2}$ are the charge of an electron, volume of the film, and partial pressure of oxygen, respectively. In the case of doped $\mathrm{CeO}_{2}$ thin films, it represents the formation and annihilation of $\mathrm{V}_{\mathrm{o}}$, due to the change in oxygen partial pressure. We considered only low $\mathrm{pO}_{2}$, because the $\mathrm{CeO}_{2}$ films in our case were grown in low $\mathrm{pO}_{2}$. For low $\mathrm{pO}_{2},\left[\mathrm{~V}_{\mathrm{o}}^{\cdot}\right]$ could be estimated from the measurement of $\mathrm{C}_{\mathrm{chem}}$ by utilizing the following equation ${ }^{44}$ :

$$
\mathrm{C}_{\text {chem }}=\frac{\mathrm{q}^{2} \mathrm{~V}_{\text {film }}}{\mathrm{kT}}\left(\left[\mathrm{Pr}_{\mathrm{Ce}}\right]_{\text {total }}-2\left[\mathrm{~V}_{\mathrm{o}}^{\cdot}\right]\right),
$$

where $\left[\mathrm{Pr}_{\mathrm{Ce}}\right]_{\text {total }}$ is the total doping concentration of $\mathrm{Pr}$ in a $\mathrm{CeO}_{2}$ thin film. Equation 3 corresponds to the trivalent dopant in $\mathrm{CeO}_{2}$. A similar equation was derived for bivalent dopant at low $\mathrm{pO}_{2}$ by replacing the the mass action 
relation of the trivalent dopant by mass action relation of the bivalent dopant. The mass action or equilibrium equation of $\mathrm{Zn}$-doped $\mathrm{CeO}_{2}$ is expressed in Eq. S2 in Supporting information S2. Mass and site conservation reactions are given by ${ }^{42}$

$$
\left[\mathrm{Zn}_{\mathrm{Ce}}^{\prime \prime}\right]+\left[\mathrm{Zn}_{\mathrm{Ce}}^{\times}\right]=\left[\mathrm{Zn}_{\mathrm{Ce}}\right]_{\mathrm{total}} \text {, }
$$

where $\left[\mathrm{Zn}_{\mathrm{Ce}}\right]_{\text {total }}$ is the total doping concentration of $\mathrm{Zn}$ in $\mathrm{CeO}_{2}$ thin films. For low $\mathrm{pO}_{2}$, the electroneutrality and mass balance relation in Equation S4 takes on the following approximation

$$
\left[\mathrm{Zn}_{\mathrm{Ce}}^{\prime \prime}\right]=\left[\mathrm{V}_{\mathrm{o}}^{\cdot \cdot}\right]-\frac{1}{2}\left[\mathrm{Ce}_{\mathrm{Ce}}^{\prime}\right] \approx\left[\mathrm{Zn}_{\mathrm{Ce}}\right]_{\mathrm{total}}
$$

It is considered that concentration of holes and Ce vacancies are negligibly small and ignored at present situation. Equation 4 can be rewritten as follows by substituting the value of $\left[\mathrm{Zn}_{\mathrm{Ce}}^{\prime \prime}\right]$ from Eq. 5

$$
\left[\mathrm{Zn}_{\mathrm{Ce}}^{\times}\right] \approx\left[\mathrm{Zn}_{\mathrm{Ce}}\right]_{\mathrm{total}}-\left[\mathrm{V}_{\mathrm{o}}^{\cdot \cdot}\right]+\frac{1}{2}\left[\mathrm{Ce}_{\mathrm{Ce}}^{\prime}\right]
$$

Substituting the values of $\left[\mathrm{Zn}_{\mathrm{Ce}}^{\prime \prime}\right]$ and $\left[\mathrm{Zn}_{\mathrm{Ce}}^{\times}\right]$from Eqs. 5 and 6 in Equation S2 yields

$$
\frac{\left[\mathrm{Zn}_{\mathrm{Ce}}\right]_{\text {total }}\left\{\left[\mathrm{Zn}_{\mathrm{Ce}}\right]_{\text {total }}+\frac{1}{2}\left[\mathrm{Ce}_{\mathrm{Ce}}^{\prime}\right]\right\} \mathrm{pO}_{2}^{1 / 2}}{\left\{\left[\mathrm{Zn}_{\mathrm{Ce}}\right]_{\text {total }}-\left[\mathrm{V}_{\mathrm{o}}^{\cdot \cdot}\right]+\frac{1}{2}\left[C e_{C e}^{\prime}\right]\right\}\left[\mathrm{O}_{\mathrm{O}}^{\times}\right]}=\mathrm{K}_{\mathrm{Zn}}
$$

Rearranging Eq. 7 yields

$$
\left[\mathrm{Zn}_{\mathrm{Ce}}\right]_{\mathrm{total}}+\frac{1}{2}\left[C e_{C e}^{\prime}\right]-\left[\mathrm{V}_{\mathrm{o}}^{\cdot}\right]=\frac{\left.\left\{\left[\mathrm{Zn}_{\mathrm{Ce}}\right]_{\mathrm{total}}\right\}^{2}+\frac{1}{2}\left[\mathrm{Zn}_{\mathrm{Ce}}\right]_{\mathrm{total}}\left[\mathrm{Ce}_{C e}^{\prime}\right]\right\} \mathrm{pO}_{2}^{1 / 2}}{\mathrm{~K}_{\mathrm{Zn}}\left[\mathrm{O}_{\mathrm{O}}^{\times}\right]}
$$

Taking derivative of Eq. 8 w.r.t $\mathrm{pO}_{2}$

$$
\frac{\partial\left[\mathrm{V}_{\mathrm{O}}\right]}{\partial \mathrm{pO}_{2}}=-\frac{1}{2} \frac{\left.\left\{\left[\mathrm{Zn}_{\mathrm{Ce}}\right]_{\text {total }}\right\}^{2}+\frac{1}{2}\left[\mathrm{Zn}_{\mathrm{Ce}}\right]_{\text {total }}\left[\mathrm{Ce}_{C e}^{\prime}\right]\right\} \mathrm{pO}_{2}^{-1 / 2}}{\mathrm{~K}_{\mathrm{Zn}}\left[\mathrm{O}_{\mathrm{O}}^{\times}\right]}
$$

Putting the value of $\frac{\partial\left[\mathrm{V}_{\ddot{\mathrm{O}}}\right]}{\partial \mathrm{pO}_{2}}$ from Eq. 9 in Eq. 3 and rearranging yields

$$
\mathrm{C}_{\text {chem }}=\frac{\left.\left.4 \mathrm{q}^{2} \mathrm{~V}_{\text {film }}\left[\mathrm{Zn}_{\mathrm{Ce}}\right]_{\text {total }}\right\}^{2}+\frac{1}{2}\left[\mathrm{Zn}_{\mathrm{Ce}}\right]_{\text {total }}\left[\mathrm{Ce}_{\mathrm{Ce}}^{\prime}\right]\right\} \mathrm{pO}_{2}^{1 / 2}}{\mathrm{kTK}_{\mathrm{Zn}}\left[\mathrm{O}_{\mathrm{O}}^{\times}\right]}
$$

Substituting Eq. 8 in Eq. 10 yields,

$$
\mathrm{C}_{\text {chem }}=\frac{4 \mathrm{q}^{2} \mathrm{~V}_{\text {film }}}{\mathrm{kT}}\left(\left[\mathrm{Zn}_{\mathrm{Ce}}\right]_{\text {total }}+\frac{1}{2}\left[C e_{C e}^{\prime}\right]-\left[\mathrm{V}_{\mathrm{o}}^{\cdot}\right]\right)
$$

Equation 11 represents the relationship between the concentration of isolated $\mathrm{V}_{\mathrm{o}}$ in $\mathrm{Zn}$-doped $\mathrm{CeO}_{2}$ films and chemical capacitance extracted by the EIS. If the doping concentration of $\mathrm{Zn}\left(\left[\mathrm{Zn}_{\mathrm{Ce}}\right]_{\text {total }}\right)$ and the concentration of reduced $\mathrm{Ce}^{3+}\left(\left[\mathrm{Ce}_{C e}^{\prime}\right]\right)$ is known in the $\mathrm{Zn}$-doped $\mathrm{CeO}_{2}$ thin films, the concentration of $\mathrm{V}_{\mathrm{o}}$ can be extracted.

$\left[\mathrm{Zn}_{\mathrm{Ce}}\right]_{\text {total }}$ and $\left[\mathrm{Ce}_{\mathrm{Ce}}^{\prime}\right]$ can be calculated from XPS data as follows assuming the cross-section of each elemental peak is the same $e^{45}$ :

$$
\begin{gathered}
{\left[\mathrm{Zn}_{\mathrm{Ce}}\right]_{\mathrm{total}}=\frac{\mathrm{A}_{\mathrm{Zn}} / \mathrm{S}_{\mathrm{Zn}}}{\sum \mathrm{A}_{\mathrm{i}} / \mathrm{S}_{\mathrm{i}}},} \\
{\left[C e^{\prime}{ }_{C e}\right]=\frac{A_{C e^{+3} / S_{C e^{+3}}}}{\sum A_{i} / S_{i}}} \\
\sum A_{i} / S_{i}=\frac{A_{Z n}}{S_{Z n}}+\frac{A_{C e^{+3}}}{S_{C e^{+3}}}+\frac{A_{O 2}}{S_{O 2}},
\end{gathered}
$$

where $\mathrm{A}_{\mathrm{Zn}}, A_{C e^{+3}}$ and $A_{O 2}$ are the areas of $\mathrm{Zn}, \mathrm{Ce}^{3+}$ and $\mathrm{O}_{2}$ peaks in XPS spectra, respectively, and the $S_{Z n}(31.861)$, $S_{\mathrm{Ce}^{+3}}(61.447)$ and $S_{\mathrm{O} 2}(2.881)$ are the atomic sensitivity factors of $\mathrm{Zn}, \mathrm{Ce}^{3+}$ and $\mathrm{O}_{2}$, respectively. The volume of the film was calculated to be $2 \mathrm{~cm} \times 2 \mathrm{~cm} \times 50 \mathrm{~nm}$ (length $\times$ width $\times$ thickness). The calculated values of [ $\left.\mathrm{V}_{\mathrm{o}}^{*}\right]$ for different doping concentrations of $\mathrm{Zn}$ is plotted in Fig. 4(c). As can be seen in Fig. 4(c), the concentration of isolated $\mathrm{V}_{\mathrm{o}}$ increases with the increase in doping concentration which was consistent with the increase in the conductivity of $6 \mathrm{ZnCeO}_{2}$ and $14 \mathrm{ZnCeO}_{2}$. However, there was a minute increase in the concentration of $\mathrm{V}_{\mathrm{o}}$ on further increasing the doping concentration from $14 \%$ to $24 \%$. As previously explained, in heavily doped samples, the 


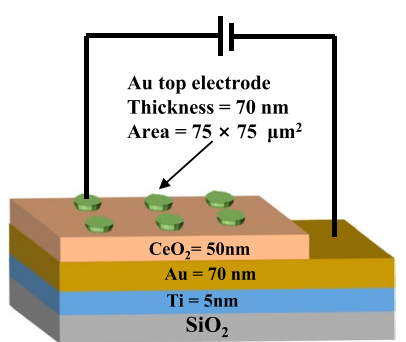

(a)

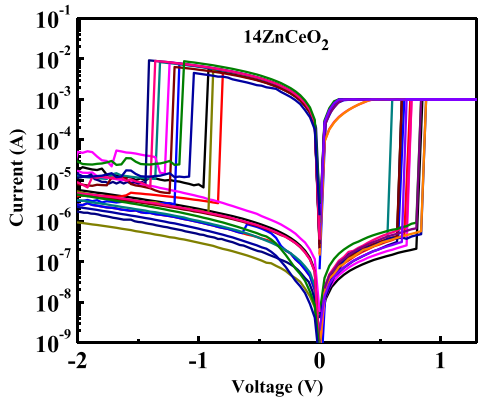

(d)

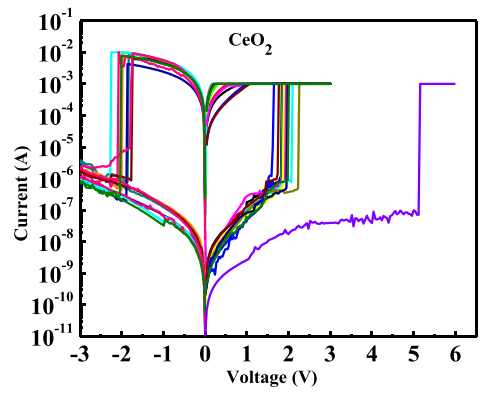

(b)

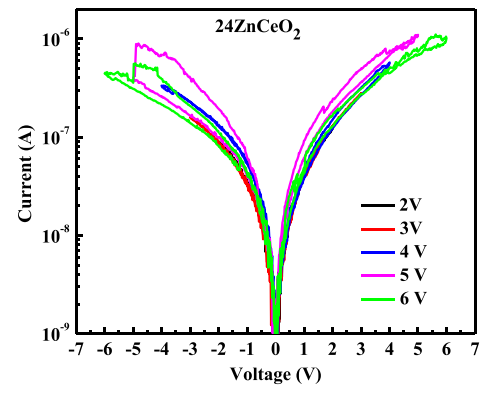

(e)

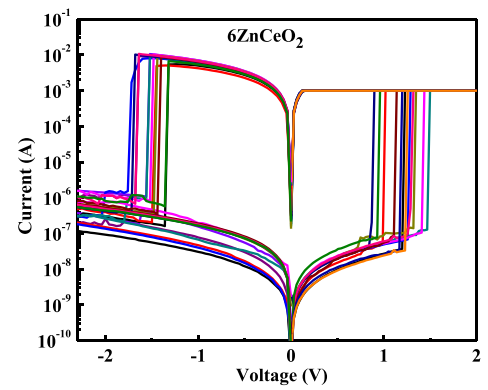

(c)

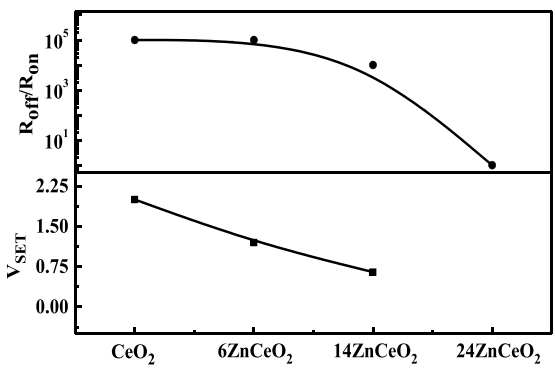

(f)

Figure 5. $\mathrm{I}-\mathrm{V}$ characteristics for (a) un-doped $\mathrm{CeO} 2$ (b) $6 \mathrm{ZnCeO}_{2}$ (c) $14 \mathrm{ZnCeO}_{2}$ (d) $24 \mathrm{ZnCeO}_{2}$, and (e) Plot of variation in $\mathrm{R}_{\text {off }} / \mathrm{R}_{\mathrm{on}}$ ratio and $\mathrm{V}_{\mathrm{SET}}$ on increasing the doping concentration.

association between $\mathrm{V}_{\mathrm{o}}$ and dopant becomes strong, and the isolated $\mathrm{V}_{\mathrm{o}}$ gets trapped in the $\left(\mathrm{Zn}, \mathrm{V}_{\mathrm{o}}\right)^{\times}$clusters. This phenomenon does not allow $\mathrm{V}_{\mathrm{o}}$ to increase considerably in heavily doped sample.

Figure 5 shows the $\mathrm{I}-\mathrm{V}$ characteristics for (b) the un-doped $\mathrm{CeO}_{2}$ (c) the $6 \mathrm{ZnCeO}_{2}$ (d) the $14 \mathrm{ZnCeO}_{2}$ (e) the $24 \mathrm{ZnCeO}_{2}$, respectively, with (a) the schematic diagram of $\mathrm{Au} / \mathrm{Zn}$-doped $\mathrm{CeO}_{2} / \mathrm{Au}$ devices. Figure 5 (f) shows the $\mathrm{R}_{\text {off }} / \mathrm{R}_{\text {on }}$ ratio and $\mathrm{V}_{\mathrm{SET}}$ on increasing the doping concentration. Both $\mathrm{R}_{\text {off }} / \mathrm{R}_{\text {on }}$ ratio and $\mathrm{V}_{\mathrm{SET}}$ decreases on increasing the doping concentration. In order to initiate the resistive switching in undoped $\mathrm{CeO}_{2}$, the electrical forming step was applied to the sample. Figure 5(b) presents the electroforming curve and subsequent bipolar resistive switching curves of the $\mathrm{CeO}_{2}$ film. The electroforming occurred at $5.2 \mathrm{~V}$. After the electroforming step, the device showed a typical resistive switching behavior with reliable repeatability of the switching cycles.

In the SET process, the device is first driven from the high resistance state (HRS) or the OFF state toward the low resistive state (LRS) or the ON state by applying a positive bias on the top electrode (Au) as shown in Fig. 5(a). The voltage at which the sharp increase in current is observed is termed as $\mathrm{V}_{\text {SET }}$. When the negative voltage is applied at the top electrode, the process is reversed. This transition of device from LRS to HRS at a particular voltage $\left(V_{\text {RESET }}\right)$, is referred as the RESET process. Without doping in the $\mathrm{CeO}_{2}$, the IV curves showed high operating voltage. According to the Raman, XPS, and EIS spectroscopies, which was for the case of the un-doped $\mathrm{CeO}_{2}$, the oxygen vacancy level was low. Hence, a large value of voltage was required to induce resistive switching was ascribed to the low level of oxygen vacancy concentration.

In the doped $\mathrm{CeO}_{2}$, the forming step was not necessary since there was already a significant amount of $\mathrm{V}_{\mathrm{o}}$. Typically, the forming process is introduced to create defects to initiate resistive switching. At low $\mathrm{Zn}$ doping concentration, a reduction in $\mathrm{V}_{\mathrm{SET}}$ was observed as shown in Fig. 5(c), which shows the effect of easy oxygen ionic motion. As a result, lower operating voltage was observed for the $6 \mathrm{ZnCeO}_{2}$ device. The on/off ratio up to $10^{5}$ was maintained for a doping concentration of $6 \% \mathrm{Zn}$. The $14 \% \mathrm{Zn}$ doping concentrations resulted in a more pronounced reduction in operating voltage. However, with this doping range, the on/off ratio was reduced to $10^{4}$. We interpreted this finding by the increased mobility of the oxygen ions due to increased oxygen vacancies. This result is consistent with the XPS and Raman spectroscopy indicating the increase in $\mathrm{Ce}^{3+}$ ions and $\mathrm{V}_{\mathrm{o}}$ related Raman modes by increasing dopant concentration. By further increasing the doping concentration up to $24 \%$, the resistive switching was diminished. At higher doping concentrations, bulk conductivity was reduced due to decreasing mobility of the isolated $\mathrm{V}_{\mathrm{o}}$ by the increased number density of the $\left(Z n, V_{o}\right)^{\times}$defect clusters. At low doping concentrations, the isolated $\mathrm{V}_{\mathrm{o}}$ existed in the $\mathrm{CeO}_{2}$ lattice but as the doping concentration increased, the number of isolated $\mathrm{V}_{\mathrm{o}}$ increased and the association between the defects and $\mathrm{V}_{\mathrm{o}}$ also occurred and formed neutral or charged clusters. The size and number density of these $\left(Z n, V_{o}\right)^{\times}$defect clusters increased slightly with the doping concentration. When their number density was small at intermediate doping (Fig. 6(a)), it was energetically more favorable for the oxygen vacancies to rearrange and initiate further reduction in operating voltage at intermediate doping concentrations. At high doping concentrations (Fig. 6(b)), when the size and number density of these clusters increased, these clusters caused hindrance in the mobility of the $V_{o}$. When these $V_{o}$ are trapped by the defect clusters, it makes it difficult for the oxygen ions to hop over the vacancies. Hence, the mobility of the oxygen ions will be reduced. Figure 5 (f) shows the results for the $V_{S E T}$ and the $R_{o f f} / R_{o n}$ ratio for the different $\mathrm{Zn}$ 
Intermediate doping

concentration

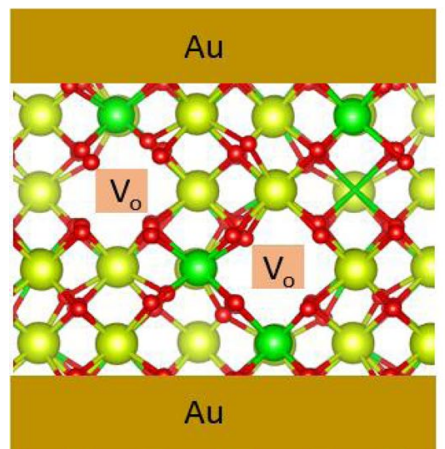

(a)
High doping

concentration

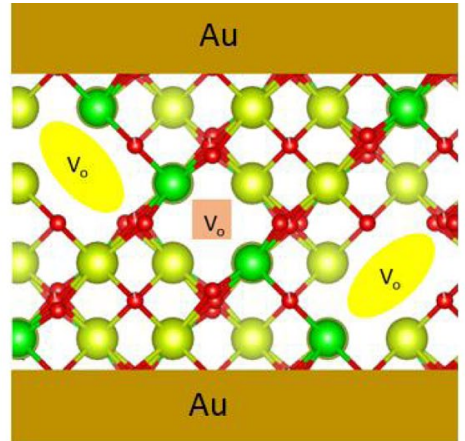

(b)

Figure 6. Representation of isolated and cluster defects at various doping levels.

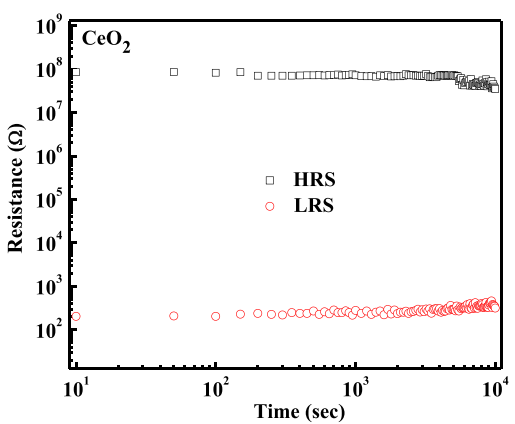

(a)

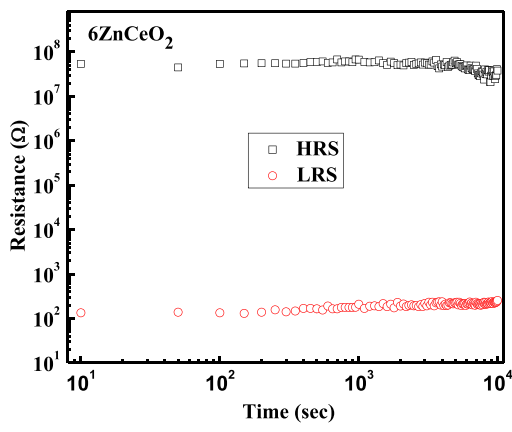

(b)

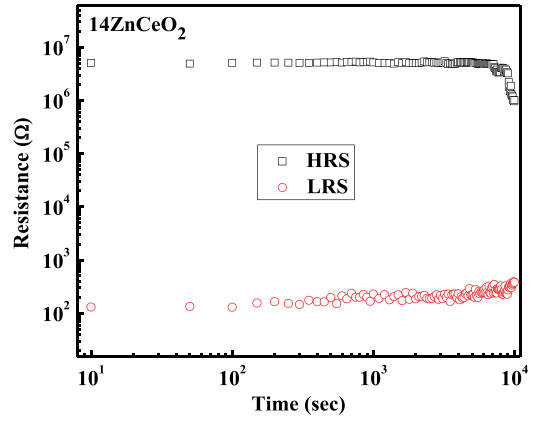

(c)

Figure 7. Retention data of (a) un-doped $\mathrm{CeO}_{2}$ (b) $6 \mathrm{ZnCeO}_{2}$, and (c) $14 \mathrm{ZnCeO}_{2}$ devices in the LRS (hollow circles) and HRS (hollow squares) at room temperature.

concentrations. A maximum in the $\mathrm{V}_{\mathrm{SET}}$ was observed for the device without doping. The $\mathrm{V}_{\mathrm{SET}}$ was minimum at an intermediate $\mathrm{Zn}$ doping concentration. At high $\mathrm{Zn}$ doping concentrations, resistive switching was diminished. Similarly, a decrease in the $\mathrm{R}_{\text {off }} / \mathrm{R}_{\text {on }}$ ratio was observed for the intermediate $\mathrm{Zn}$ doping concentrations. Comparing these results to the ionic conductivity, we demonstrated that there is a connection between the ionic conductivity of the oxide and the switching characteristics such as $V_{S E T}$ and $R_{o f f} / R_{o n}$ in resistive switching devices. This reduction in the $\mathrm{R}_{\text {off }} / \mathrm{R}_{\text {on }}$ ratio and the $\mathrm{V}_{\mathrm{SET}}$ was ascribed to the increase in ionic conductivity by increasing the doping concentration from $6 \%$ to $14 \%$. The association of ionic conductivity of the $\mathrm{Zn}$-doped $\mathrm{CeO}_{2}$ with different $\mathrm{Zn}$ concentrations is explained in relation to the impedance spectroscopy analysis. The device to device variation of undoped $\mathrm{CeO} 2,6 \mathrm{ZnCeO} 2$, and $14 \mathrm{ZnCeO} 2$ is given in Figure S5. The statistical data indicate that there is no significant variation in the $\mathrm{V}_{\mathrm{SET}}$.

The retention measurement results of the un-doped $\mathrm{CeO}_{2}, 6 \mathrm{ZnCeO}_{2}$, and $14 \mathrm{ZnCeO}_{2}$ devices at room temperature by applying reading bias of $+0.2 \mathrm{~V}$ are shown in Fig. $7(\mathrm{a}-\mathrm{c})$. The $\mathrm{R}_{\mathrm{off}} / \mathrm{R}_{\text {on }}$ ratio was maintained at $10^{5}$ with no significant degradation in resistance after $10^{4} \mathrm{sec}$ in the un-doped $\mathrm{CeO}_{2}$, and $6 \mathrm{ZnCeO}_{2}$. However, the on/off ratio was reduced to $10^{4}$ in the $14 \mathrm{ZnCeO}_{2}$ device. This decrease in the $\mathrm{R}_{\text {off }} / \mathrm{R}_{\text {on }}$ ratio was associated with the increase in ionic conductivity of oxygen ions by increasing the doping concentration from a $6 \%$ to a $14 \%$ doping concentration as illustrated in Fig. 5(f), which caused low $\mathrm{R}_{\text {off }} / \mathrm{R}_{\text {on }}$ ratio. $\mathrm{Zn}$-doped $\mathrm{CeO}_{2}$ devices with the intermediate doping level showed a great potential for nonvolatile memory applications with the low $V_{\text {SET }} / V_{\text {RESET }}$, high $R_{\text {off }} / R_{\text {on }}$ ratio, and good retention characteristics.

The endurance data for un-doped $\mathrm{CeO}_{2}, 6 \mathrm{ZnCeO}_{2}$, and $14 \mathrm{ZnCeO}_{2}$ are given in Figure $\mathrm{S} 7$. The $\mathrm{R}_{\text {off }} / \mathrm{R}_{\text {on }}$ ratio of $\mathrm{CeO}_{2}$ and $6 \mathrm{ZnCeO}_{2}$ devices was maintained at $10^{5}$ without any significant degradation up to 250 cycles. Although the on/off ratio of $14 \mathrm{ZnCeO}$ device was reduced to $10^{4}$, no degradation of $\mathrm{R}_{\text {off }} / \mathrm{R}_{\text {on }}$ ratio was observed.

\section{Conclusions}

$\mathrm{Zn}$-doped $\mathrm{CeO}_{2}$ active layer is utilized for resistive switching. Raman spectroscopy is employed to study the structural modification introduced by the dopant in the host lattice of $\mathrm{CeO}_{2}$. An increase in FWHM of the characteristics peak of $\mathrm{CeO}_{2}\left(460 \mathrm{~cm}^{-1}\right)$ and the enhancement of the defect related peak $\left(560 \mathrm{~cm}^{-1}\right)$ confirms the uniform doping of $\mathrm{Zn}$ in $\mathrm{CeO}_{2}$ and the existence of $\left(\mathrm{Zn}, V_{o}\right)^{\times}$defect clusters in $\mathrm{Zn}$-doped $\mathrm{CeO}_{2}$. Increased doping of $\mathrm{Zn}$ in 
$\mathrm{CeO}_{2}$ leads to the formation of more oxygen vacancies in $\mathrm{Zn}$ doped $\mathrm{CeO}_{2}$. Increase in oxygen vacancies with an increasing doping concentration results in reduction of operating voltage in $6 \mathrm{ZnCeO}_{2}$ and $14 \mathrm{ZnCeO}_{2}$ devices as compared to $\mathrm{CeO}_{2}$ device. A further increase in the doping concentration leads to the diminishing of resistive switching behavior in a $24 \mathrm{CZnO}$ device. This behavior is explained by the increased number density of $\left(\mathrm{Zn}, V_{o}\right)^{\times}$ defect clusters which decrease the mobility of $\mathrm{V}_{\mathrm{o}}$ in the highly doped $\mathrm{CeO}_{2}$.

Received: 25 July 2019; Accepted: 2 December 2019;

Published online: 18 December 2019

\section{References}

1. Chua, L. O. \& Kang, S. M. Memristive devices and systems. Proceedings of the IEEE 64, 209-223 (1976).

2. Strukov, D. B., Snider, G. S., Stewart, D. R. \& Williams, R. S. The missing memristor found. nature 453, 80 (2008).

3. Ielmini, D. \& Milo, V. Physics-based modeling approaches of resistive switching devices for memory and in-memory computing applications. Journal of Computational Electronics 16, 1121-1143 (2017).

4. Kilner, J. A. \& Burriel, M. Materials for intermediate-temperature solid-oxide fuel cells. Annual Review of Materials Research 44, 365-393 (2014)

5. Andersson, D. A., Simak, S. I., Skorodumova, N. V., Abrikosov, I. A. \& Johansson, B. Optimization of ionic conductivity in doped ceria. Proceedings of the National Academy of Sciences 103, 3518-3521 (2006).

6. Balducci, G., Islam, M. S., Kašpar, J., Fornasiero, P. \& Graziani, M. Reduction process in $\mathrm{CeO}_{2}-\mathrm{MO}$ and $\mathrm{CeO}_{2}-\mathrm{M}_{2} \mathrm{O}_{3}$ mixed oxides: a computer simulation study. Chemistry of materials 15, 3781-3785 (2003).

7. Lucid, A. K., Keating, P. R., Allen, J. P. \& Watson, G. W. Structure and Reducibility of $\mathrm{CeO}_{2}$ Doped with Trivalent Cations. The Journal of Physical Chemistry C 120, 23430-23440 (2016).

8. Li, Z.-P., Mori, T., Zou, J. \& Drennan, J. Defects clustering and ordering in di-and trivalently doped ceria. Materials Research Bulletin 48, 807-812 (2013).

9. Younis, A., Chu, D., Mihail, I. \& Li, S. Interface-engineered resistive switching: $\mathrm{CeO}_{2}$ nanocubes as high-performance memory cells. Acs Appl Mater Inter 5, 9429-9434 (2013).

10. Ismail, M. et al. Forming-free bipolar resistive switching in nonstoichiometric ceria films. Nanoscale research letters $\mathbf{9}, 45(2014)$

11. Yang, S.-M. et al. Cerium oxide nanocrystals for nonvolatile memory applications. Applied Physics Letters 91, 262104 (2007).

12. Lin, C.-Y., Lee, D.-Y., Wang, S.-Y., Lin, C.-C. \& Tseng, T.-Y. Reproducible resistive switching behavior in sputtered CeO 2 polycrystalline films. Surface and Coatings Technology 203, 480-483 (2008).

13. Younis, A., Chu, D. \& Li, S. Oxygen level: the dominant of resistive switching characteristics in cerium oxide thin films. Journal of Physics D: Applied Physics 45, 355101 (2012).

14. Rana, A. M. et al. Endurance and cycle-to-cycle uniformity improvement in tri-layered $\mathrm{CeO} 2 / \mathrm{Ti} / \mathrm{CeO} 2$ resistive switching devices by changing top electrode material. Scientific reports 7, 39539 (2017).

15. Dou, C. et al. Resistive switching behavior of a $\mathrm{CeO}_{2}$ based ReRAM cell incorporated with Si buffer layer. Microelectronics Reliability 52, 688-691 (2012).

16. Liao, Z. et al. Electrode engineering for improving resistive switching performance in single crystalline CeO2 thin films. Solid State Electron 72, 4-7 (2012).

17. Kehoe, A. B., Scanlon, D. O. \& Watson, G. W. Role of lattice distortions in the oxygen storage capacity of divalently doped CeO ${ }_{2}$. Chemistry of materials 23, 4464-4468 (2011)

18. Khan, M. M., Khan, W., Ahamed, M. \& Alhazaa, A. N. Microstructural properties and enhanced photocatalytic performance of Zn doped $\mathrm{CeO}_{2}$ nanocrystals. Scientific reports 7, 12560 (2017).

19. Ismail, M. et al. Improved endurance and resistive switching stability in ceria thin films due to charge transfer ability of $\mathrm{Al}$ dopant. ACS applied materials \& interfaces 8, 6127-6136 (2016).

20. Ismail, M., Ahmed, E., Rana, A. M., Talib, I. \& Nadeem, M. Y. Coexistence of bipolar and unipolar resistive switching in Al-doped ceria thin films for non-volatile memory applications. Journal of Alloys and Compounds 646, 662-668 (2015).

21. Kellici, S. et al. High-throughput continuous hydrothermal flow synthesis of Zn-Ce oxides: unprecedented solubility of Zn in the nanoparticle fluorite lattice. Philosophical Transactions of the Royal Society A: Mathematical, Physical and Engineering Sciences 368, 4331-4349 (2010).

22. Liu, Y. et al. Superionic conductivity of $\mathrm{Sm}^{3+}, \mathrm{Pr}^{3+}$, and $\mathrm{Nd}^{3+}$ triple-doped ceria through bulk and surface two-step doping approach. ACS applied materials \& interfaces 9, 23614-23623 (2017).

23. Kim, D. J. Lattice Parameters, Ionic Conductivities, and Solubility Limits in Fluorite-Structure $\mathrm{MO} 2 \mathrm{Oxide}\left[\mathrm{M}=\mathrm{Hf}^{4+}, \mathrm{Zr}^{4+}, \mathrm{Ce}^{4+}\right.$, $\mathrm{Th}^{4+}, \mathrm{U}^{4+}$ ] Solid Solutions. Journal of the American Ceramic Society 72, 1415-1421 (1989).

24. Park, D., Griffith, J. \& Nowick, A. Oxygen-ion conductivity and defect interactions in yttria-doped ceria. Solid State Ionics 2, 95-105 (1981).

25. Islam, M. S. \& Davies, R. A. Atomistic study of dopant site-selectivity and defect association in the lanthanum gallate perovskite. Journal of Materials Chemistry 14, 86-93 (2004).

26. Lee, W., Chen, S.-Y., Tseng, E., Gloter, A. \& Chen, C.-L. Study of Defect Structure in Ferromagnetic Nanocrystalline CeO ${ }_{2}$ : Effect of Ionic Radius. The Journal of Physical Chemistry C 120, 14874-14882 (2016).

27. Kilner, J. Defects and conductivity in ceria-based oxides. Chemistry Letters 37, 1012-1015 (2008).

28. Andersson, D. A., Simak, S. I., Skorodumova, N. V., Abrikosov, I. A. \& Johansson, B. Optimization of ionic conductivity in doped ceria. Proceedings of the National Academy of Sciences of the United States of America 103, 3518-3521 (2006).

29. Muthukkumaran, K., Bokalawela, R., Mathews, T. \& Selladurai, S. RETRACTED ARTICLE: Determination of dopant of ceria system by density functional theory. Journal of materials science 42, 7461-7466 (2007).

30. Deshpande, S., Patil, S., Kuchibhatla, S. V. \& Seal, S. Size dependency variation in lattice parameter and valency states in nanocrystalline cerium oxide. Applied Physics Letters 87, 133113 (2005)

31. Jin, F., Shen, Y., Wang, R. \& He, T. Double-perovskite $\mathrm{PrBaCo}_{2} / 3 \mathrm{Fe}_{2} / 3 \mathrm{Cu}_{2} / 3 \mathrm{O}_{5+\delta}$ as cathode material for intermediate-temperature solid-oxide fuel cells. Journal of Power Sources 234, 244-251 (2013).

32. Yang, N. et al. Role of associated defects in oxygen ion conduction and surface exchange reaction for epitaxial samaria-doped ceria thin films as catalytic coatings. ACS applied materials \& interfaces 8, 14613-14621 (2016).

33. Schweiger, S., Kubicek, M., Messerschmitt, F., Murer, C. \& Rupp, J. L. A microdot multilayer oxide device: let us tune the strain-ionic transport interaction. ACS nano 8, 5032-5048 (2014).

34. Ackermann, S. et al. Kinetics of $\mathrm{CO}_{2}$ reduction over nonstoichiometric ceria. The Journal of Physical Chemistry C 119, 16452-16461 (2015).

35. Shi, Y., Bork, A. H., Schweiger, S. \& Rupp, J. L. M. The effect of mechanical twisting on oxygen ionic transport in solid-state energy conversion membranes. Nature materials 14, 721 (2015).

36. Rupp, J. L. et al. Scalable oxygen-ion transport kinetics in metal-oxide films: impact of thermally induced lattice compaction in acceptor doped ceria films. Advanced Functional Materials 24, 1562-1574 (2014). 
37. Taniguchi, T. et al. Identifying defects in ceria-based nanocrystals by UV resonance Raman spectroscopy. The Journal of Physical Chemistry C 113, 19789-19793 (2009).

38. Guo, M., Lu, J., Wu, Y., Wang, Y. \& Luo, M. UV and visible Raman studies of oxygen vacancies in rare-earth-doped ceria. Langmuir 27, 3872-3877 (2011)

39. Guo, X., Sigle, W. \& Maier, J. Blocking Grain Boundaries in Yttria-Doped and undoped ceria ceramics of high purity. Journal of the American Ceramic Society 86, 77-87 (2003).

40. Göbel, M. C., Gregori, G., Guo, X. \& Maier, J. Boundary effects on the electrical conductivity of pure and doped cerium oxide thin films. Physical Chemistry Chemical Physics 12, 14351-14361 (2010).

41. Göbel, M. C., Gregori, G. \& Maier, J. Mixed conductivity in nanocrystalline highly acceptor doped cerium oxide thin films under oxidizing conditions. Physical Chemistry Chemical Physics 13, 10940-10945 (2011).

42. Chen, D., Bishop, S. R. \& Tuller, H. L. Non-stoichiometry in Oxide Thin Films: A Chemical Capacitance Study of the PraseodymiumCerium Oxide System. Advanced Functional Materials 23, 2168-2174 (2013).

43. Pijolat, M., Prin, M., Soustelle, M., Touret, O. \& Nortier, P. Thermal stability of doped ceria: experiment and modelling. Journal of the Chemical Society, Faraday Transactions 91, 3941-3948 (1995).

44. Li, Z.-P. et al. Cerium-reduction-induced defects clustering, ordering, and associated microstructure evolution in yttrium-doped ceria. The Journal of Physical Chemistry C 116, 5435-5443 (2012).

45. Jabłoński, A. Quantitative surface analysis by X-ray photoelectron spectroscopy. Polish Journal of Chemistry 74, 1533-1566 (2000).

\section{Acknowledgements}

This research was supported by the Basic Research Program (2016R1D1A1B01009537) and the Nano Material Technology Development Program (2015M3A7B7045496,) through the National Research Foundation of Korea (NRF) funded by the Ministry of Science, ICT \& Future Planning. This research was supported by the MOTIE (Ministry of Trade, Industry \& Energy (10080581) and KSRC (Korea Semiconductor Research Consortium) support program for the development of the future semiconductor device. This research was supported by Korea Electric Power Corporation (Grant number: R19XO01-17).

\section{Author contributions}

S.R. and D.K. planned the project and wrote the manuscript. S.R. worked on device fabrication, device characterization and data collection. H.K. and M.F.K. helped in device fabrication and experimental measurements. D.K., J.H.H. and A.D.L. analyzed and conducted the interpretation of the results. All authors discussed the development of research and reviewed the manuscript in detail.

\section{Competing interests}

The authors declare no competing interests.

\section{Additional information}

Supplementary information is available for this paper at https://doi.org/10.1038/s41598-019-55716-4.

Correspondence and requests for materials should be addressed to D.-k.K.

Reprints and permissions information is available at www.nature.com/reprints.

Publisher's note Springer Nature remains neutral with regard to jurisdictional claims in published maps and institutional affiliations.

Open Access This article is licensed under a Creative Commons Attribution 4.0 International License, which permits use, sharing, adaptation, distribution and reproduction in any medium or format, as long as you give appropriate credit to the original author(s) and the source, provide a link to the Creative Commons license, and indicate if changes were made. The images or other third party material in this article are included in the article's Creative Commons license, unless indicated otherwise in a credit line to the material. If material is not included in the article's Creative Commons license and your intended use is not permitted by statutory regulation or exceeds the permitted use, you will need to obtain permission directly from the copyright holder. To view a copy of this license, visit http://creativecommons.org/licenses/by/4.0/.

(C) The Author(s) 2019 